\title{
Uptake of governmental social protection and financial hardship during drug-resistant tuberculosis treatment in Rio de Janeiro, Brazil
}

\author{
William E. Rudgard ${ }^{1}$, Nancy S. das Chagas $^{2}$, Regina Gayoso² ${ }^{2}$ \\ Mauricio L. Barreto ${ }^{3,4}$, Delia Boccia ${ }^{1}$, Liam Smeeth ${ }^{5}$, Laura C. Rodrigues ${ }^{1,4}$, \\ Knut Lönnroth ${ }^{6}$, Elizabeth Williamson ${ }^{7}$ and Ethel L.N. Maciel ${ }^{8}$
}

Affiliations: 'Dept of Infectious Disease Epidemiology, London School of Hygiene and Tropical Medicine (LSHTM), London, UK. ${ }^{2}$ Centro de Referencia Helio Fraga, Escola Nacional de Saude (ENSP), FIOCRUZ, Rio de Janeiro, Brazil. ${ }^{3}$ Instituto de Saude de Coletiva, Universidade Federal de Bahia (UFBA). Salvador, Brazil. ${ }^{4}$ Centro de Integracao de Dados e Conhecimentos para Saude (CIDACS), Instituto Goncalo Moniz (IGM), FIOCRUZ, Salvador, BA, Brazil. ${ }^{5}$ Dept of Non-communicable Disease Epidemiology, London School of Hygiene and Tropical Medicine (LSHTM), London, UK. ' ${ }^{6}$ Dept of Public Health Sciences, Karolinska Institutet, Stockholm, Sweden. ${ }^{7}$ Dept of Medical Statistics, London School of Hygiene and Tropical Medicine (LSHTM), London, UK. ${ }^{8}$ Laboratorio de Epidemiologia, Universidade Federal de Espirito Santo (UFES), Vitoria, Brazil.

Correspondence: William E. Rudgard, Dept of Infectious Disease Epidemiology, London School of Hygiene and Tropical Medicine, Keppel St, Bloomsbury, London, WC1E 7HT, UK. E-mail: willrudgardahotmail.co.uk

@ERSpublications

Governmental social protection contributes to preventing household financial hardship from drugresistant tuberculosis in Brazil http://ow.ly/jxZL30iPqOo

Cite this article as: Rudgard WE, das Chagas NS, Gayoso R, et al. Uptake of governmental social protection and financial hardship during drug-resistant tuberculosis treatment in Rio de Janeiro, Brazil. Eur Respir J 2018; 51: 1800274 [https://doi.org/10.1183/13993003.00274-2018].

\section{End TB Strategy: universal health coverage and social protection for preventing financial hardship}

Despite most countries offering tuberculosis (TB) diagnosis and treatment free of charge, TB-related costs remain an important barrier for accessing TB care [1]. TB-related costs include direct medical expenses (e.g. consultations), direct non-medical expenses (e.g. transport and food for accessing health services) and lost income from time off work related to disability, discrimination and/or infection control laws [2]. With the treatment duration for drug-resistant TB lasting up to 24 months, affected households are especially vulnerable to TB-related costs [1]. In Cambodia, Ecuador, Ethiopia, Indonesia, Kazakhstan and Peru, average drug-resistant TB-related costs range between $75 \%$ and $223 \%$ of annual household income [3-7].

The World Health Organization's (WHO's) End TB Strategy mandates that by 2025 nobody should experience financial hardship because of TB [8]. Countries are encouraged to monitor progress towards this milestone by collecting regular estimates of the prevalence of financial hardship due to TB [9]. Financial hardship might be measured as total costs exceeding $20 \%$ of pre-illness annual household income; relying on a financial coping strategy (i.e. taking a loan or selling assets); or total costs that are impoverishing $[9,10]$.

To prevent financial hardship from TB, countries should facilitate people's access to universal health coverage (UHC) and social protection [9]. Worldwide, Brazil is increasingly seen as a model country for inclusive social development. Here, the national Unified Health System provides all health services free of 
charge, and three governmental social protection policies (Auxilio-Doenca, Bolsa Familia and Beneficio da Prestacao Continuada (BPC)) are designed to help people manage financial consequences of illness [11-13]. Currently, it is unknown if these measures protect the most vulnerable TB-affected households, those experiencing drug-resistant TB, from financial hardship.

\section{Evaluating uptake of social protection and financial hardship among drug-resistant} TB-affected households in Rio de Janeiro

In May 2016, there were 1601 people with drug-resistant TB in Brazil ( 0.77 cases per 100000 population), with $29 \%$ residing in Rio de Janeiro state [14]. To evaluate whether uptake of social protection during treatment is associated with reduced risk of experiencing financial hardship, we conducted a crosssectional survey of people with drug-resistant TB who had been receiving treatment for at least 1 month and were attending the outpatient clinic of the Professor Helio Fraga reference centre (CRPHF) in Rio de Janeiro state. Ethical approval was obtained from the Escola Nacional de Saúde Pública Sérgio Arouca ethics committee (1.4238.240, CAEE: 53187516.0000.5240). All participants gave written informed consent before participating.

Data were collected by two social workers between June and October 2016, using a local adaptation of the field-testing version of the WHO's TB patient cost survey instrument detailed and available online [15]. Questions on pre-diagnostic healthcare-seeking behaviours and costs incurred during previous courses of TB treatment were excluded because of concerns about reporting accuracy for events experienced far in the past. The revised questionnaire was pre-tested for clarity on three patients. Monetary values were collected in Brazilian Real (BRL) and converted to 2016 United States Dollar (USD) (BRL 3.5=USD 1.0) [16].

We measured direct expenses as monthly expenses accessing directly observed therapy (DOT) and the CRPHF extrapolated over participants' prescribed treatment (mean 17.6 months), added to any expenses for TB-related transport accessing a hospital, supplementary food and/or private healthcare. Lost income was the difference in monthly household income pre-illness versus during treatment extrapolated over participants' prescribed treatment [17]. Social protection was the monthly value of payments received because of drug-resistant TB extrapolated over participants' prescribed treatment. All values were self-reported. Total costs were calculated as direct expenses plus lost income after subtracting social protection.

The exposure variable was uptake of governmental social protection from Auxilio-Doenca, Bolsa Familia and/or BPC because of drug-resistant TB. The outcome, financial hardship, included separately incurring total costs $\geqslant 20 \%$ of pre-illness annual household income, using a financial coping strategy, or incurring total monthly costs that pushed pre-illness monthly household income per capita below Brazil's 2016 poverty line (USD 48.6 per month) [18], and experiencing all three situations simultaneously. We investigated the association between uptake of social protection and these four measures of financial hardship by multivariable logistic regression adjusting for socioeconomic and clinical variables associated with the outcome at $\mathrm{p}<0.1$, and the two a priori confounding variables sex and age. The likelihood ratio test was used to assess the association of exposure variables with dependent variables.

\section{Summary of social protection uptake and financial hardship among drug-resistant TB-affected households in Rio de Janeiro}

In the survey period, 131 people were invited to participate in the survey. Six had not completed 1 month of treatment, five did not give consent to participate, and one was excluded from the analysis because of implausible income data, leaving 119 participants (68\% male; mean age 42 years; ethnicity: 48\% brown, $29 \%$ black, $23 \%$ white, $1 \%$ indigenous). Before drug-resistant TB, most participants had a pre-illness monthly household income per capita of less than one minimum salary (63\%), and were the principal household income provider (53\%). Some received social protection before drug-resistant TB (16\%). Most had acquired rather than primary drug-resistant TB (55\%) and multidrug-resistant TB (3\% suspected, $29 \%$ mono-/poly-resistant, 60\% multidrug-resistant, 9\% extensively drug-resistant).

Overall, 38\% of participants reported uptake of social protection because of drug-resistant TB. Among them, $80 \%$ began receiving Auxilio-Doenca, 7\% Auxilio-Doenca and Bolsa Familia, 9\% Bolsa Familia, and $4 \%$ BPC. Participants taking up social protection were more likely to be male $(\mathrm{p}=0.005)$, younger $(\mathrm{p}=0.06)$, and in paid employment before drug-resistant TB $(\mathrm{p}=0.08)$.

Mean \pm SD direct expenses were USD $809 \pm 601$, representing $14 \pm 17 \%$ of annual household income. Lost income was USD $6207 \pm 6671$, representing $81 \pm 54 \%$ of annual household income. Social protection payments were USD $1970 \pm 2897$. Total costs, after subtracting social protection, were USD 5046 \pm 6290 , representing $64 \pm 58 \%$ of annual household income. Participants taking up social protection were more likely to incur lower total costs $(\mathrm{p}=0.005)$. 


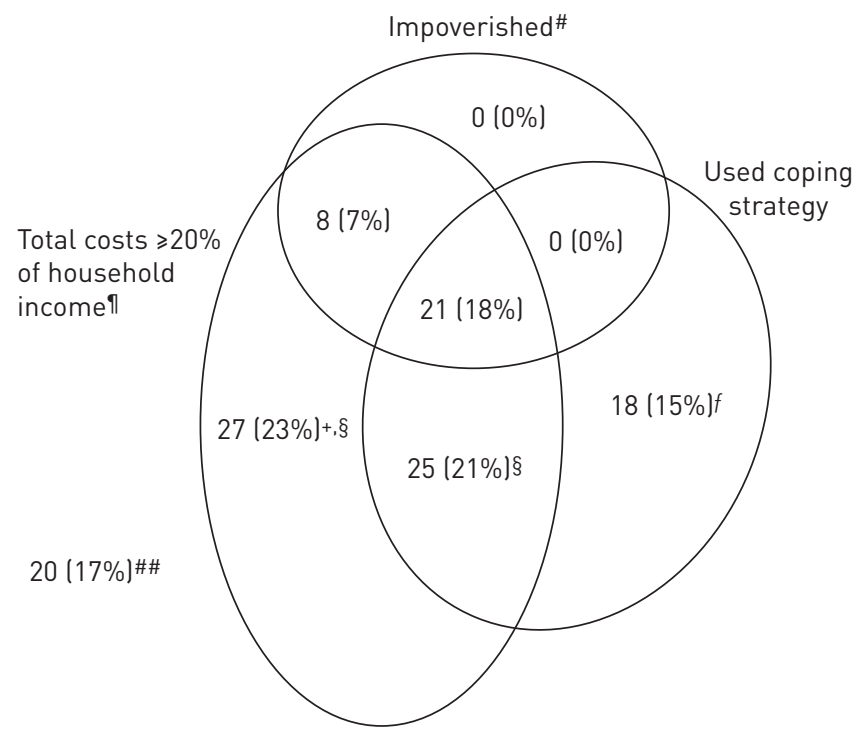

FIGURE 1 Summary of financial hardship across study participants $(n=119)$. The area of each ellipse is proportional to the number of participants in that set. The area-proportional Venn diagram was drawn using eulerAPE [19]. \#: defined using Brazil's 2016 poverty line of monthly household income per capita of USD 48.6 per month [18]; ${ }^{\text {ๆ: }}$ pre-illness annual household income; ${ }^{+}$: one participant had missing data on use of coping strategies; ${ }^{\S}$ : one participant was in poverty pre-illness; ${ }^{f}$ : two participants had pre-illness annual household income USD 0 , and were in poverty pre-illness; ${ }^{\# \#}$ : one participant had pre-illness annual household income USD 0, and was in poverty pre-illness.

Overall, $68 \%$ of participants incurred total costs $\geqslant 20 \%$ of household income, $54 \%$ used a coping strategy, $24 \%$ were impoverished and $18 \%$ experienced all three hardships (figure 1). In multivariable logistic regression, uptake of social protection was independently associated with lower risk of incurring total costs $\geqslant 20 \%$ of household income $(\mathrm{p}=0.04)$, impoverishment $(\mathrm{p}=0.002)$ and experiencing all three hardships $(\mathrm{p}<0.001)$, but not with using a coping strategy $(\mathrm{p}=0.58)$ (table 1$)$.

\section{Summary of lessons learnt and next steps forward}

In Rio de Janeiro, total costs incurred during treatment result in financial hardship for many drug-resistant TB-affected households. The main contributor to total costs is lost income. Uptake of governmental social protection because of drug-resistant TB is common, and is associated with reduced likelihood of experiencing financial hardship, especially multiple kinds simultaneously.

TABLE 1 Multivariable logistic regression assessing the association between uptake of social protection and financial hardship

\begin{tabular}{lcc} 
Financial hardship & OR $(\mathbf{9 5} \%$ CI) & p-value \\
\hline Total costs $\geqslant \mathbf{2 0 \%}$ of household income $^{\#}$ & $0.37(0.14-0.94)^{f}$ & 0.04 \\
Used coping strategy $^{\pi}$ & $1.31(0.50-3.47)^{\# \#}$ & 0.58 \\
Impoverished $^{+}$ & $0.16(0.04-0.54)^{\text {I17 }}$ & 0.002 \\
All three financial hardships $^{\S}$ & $0.01(0.00-0.07)^{++}$ & $<0.001$
\end{tabular}

Socioeconomic and clinical characteristics associated $(p<0.1)$ with outcomes in univariable logistic regression were included in multivariable logistic regression models. ${ }^{\text {: }}$ : pre-illness annual household income; three participants with pre-illness annual household income USD 0 were excluded, so $n=116$. ๆ: one participant with missing data on use of coping strategies was excluded, so $n=118 .^{+}$: defined using Brazil's 2016 poverty line of monthly household income per capita of USD 48.6 per month [18]; five participants in poverty pre-illness were excluded, so $n=114 .{ }^{\S}$ : six participants with either pre-illness annual household income USD 0 , missing data on use of coping strategies, or in poverty pre-illness were excluded, so $n=113 .{ }^{f}$ : mutually adjusted for sex, age, education, acquired drug-resistant tuberculosis (TB), and time to directly observed therapy (DOT) clinic. ${ }^{\# \#: ~ m u t u a l l y ~ a d j u s t e d ~ f o r ~ s e x, ~ a g e, ~ p r e-i l l n e s s ~ h o u s e h o l d ~}$ head, pre-illness household income per capita, acquired drug-resistant TB, and time to DOT clinic. กๆ: mutually adjusted for sex, age, education, and pre-illness household income per capita. ${ }^{++}$: mutually adjusted for sex, age, pre-illness household head, pre-illness household income per capita, acquired drug-resistant TB, and time to DOT clinic. 
To our knowledge, this is the first attempt to evaluate the association between uptake of governmental social protection and financial hardship among drug-resistant TB-affected households [3-7]. Our results are consistent with trial evidence from Lima, Peru, demonstrating the effectiveness of a non-governmental social protection intervention to defray TB-related catastrophic costs, and extend it to real-world governmental measures [3]. A survey from South Africa explored uptake of governmental social protection among people with TB, but did not evaluate its association with financial hardship [5].

Limitations include the survey's small sample size, which barred stratification of our analysis by potential effect modifiers (e.g. uptake of distinct social protection measures). Nevertheless, there was adequate power to detect an association between our exposure and outcome. The survey's cross-sectional design might have underestimated the prevalence of using a coping strategy and uptake of social protection, as the risk of these activities is likely to accumulate over treatment. Our use of four indicators of financial hardship ensures our conclusions are robust to any potential misclassification.

Our results highlight that even where UHC and social protection measures are available, efforts are still needed to protect all drug-resistant TB-affected households from financial hardship. In Rio de Janeiro state, some municipalities provide vouchers to defray patients' transport expenses for CRPHF visits. Sharing of these experiences between municipal authorities should be encouraged. People's access to social protection should also be facilitated, for example by explicit inclusion of the disabling profile of drug-resistant $\mathrm{TB}$ in the eligibility criteria of BPC, the government's disability grant. Strengthening of labour unions would also support transitions to a more formal labour market, which would enable greater access to Auxilio-Doenca [20]. Helping previously employed people to restart work when they are fit would also avoid long absences from work.

While UHC and social protection are available across Brazil, marked socioeconomic differences limit the generalisability of our results to other regions. For a more complete understanding of the association between uptake of social protection and financial hardship there is need for a nationally representative sample of drug-resistant TB-affected households. This should be followed up over time to better capture the complex dynamics of financial hardship.

Outside of Brazil, access to UHC and social protection remains low in many countries [21]. Nevertheless, progress is being made on both these fronts worldwide [22, 23]. A country-level modelling study highlights seven other low- and middle-income countries where governmental social protection is available to TB-affected households [24]. Individual-level research is now needed to investigate if TB-affected households are accessing these measures and, as we have done in Rio de Janeiro, evaluate if their uptake is associated with reduced risk of financial hardship.

Acknowledgements: We would like to thank the World Health Organization patient cost task force for supplying their questionnaire; Maria da Conceição Souza e Souza (Universidade Federal do Rio de Janeiro, Rio de Janeiro, Brazil) and Vilson Rodrigues Carneiro e Janine (Pontificia Universidade Católica do Rio de Janeiro, Rio de Janeiro, Brazil) for their help in collecting the data used in the paper; and Sanni Ali and Elizabeth Brickley (both London School of Hygiene and Tropical Medicine, London, UK) for their insightful comments and intellectual contribution to the content of the paper.

Conflict of interest: W.E. Rudgard reports grants from Medical Research Council (MRC), during the conduct of the study. L. Smeeth reports a fellowship grant from the Wellcome Trust, during the conduct of the study; grants from the Wellcome Trust, the MRC and the National Institute for Health Research (NIHR) outside the submitted work; and grants and personal fees from GSK, for advisory work unrelated to this report or its content. He is also a Trustee of the British Heart Foundation.

Support statement: Funding was received from the Medical Research Council (MR/K006584/1) and the Wellcome Trust (098504/Z/12/Z). Funding information for this article has been deposited with the Crossref Funder Registry.

\section{References}

1 Tanimura T, Jaramillo E, Weil D, et al. Financial burden for tuberculosis patients in low- and middle-income countries: a systematic review. Eur Respir J 2014; 43: 1763-1775.

2 Morris MD, Quezada L, Bhat P, et al. Social, economic, and psychological impacts of MDR-TB treatment in Tijuana, Mexico: a patient's perspective. Int J Tuberc Lung Dis 2013; 17: 954-960.

3 Wingfield T, Boccia D, Tovar M, et al. Defining catastrophic costs and comparing their importance for adverse tuberculosis outcome with multi-drug resistance: a prospective cohort study, Peru. PLoS Med 2014; 11: e1001675.

4 Rouzier VA, Oxlade O, Verduga R, et al. Patient and family costs associated with tuberculosis, including multidrug-resistant tuberculosis, in Ecuador. Int J Tuberc Lung Dis 2010; 14: 1316-1322.

5 Ramma L, Cox H, Wilkinson L, et al. Patients' costs associated with seeking and accessing treatment for drug-resistant tuberculosis in South Africa. Int J Tuberc Lung Dis 2015; 19: 1513-1519.

6 van den Hof S, Collins D, Hafidz F, et al. The socioeconomic impact of multidrug resistant tuberculosis on patients: results from Ethiopia, Indonesia and Kazakhstan. BMC Infect Dis 2016; 16: 470.

7 Pichenda K, Nakamura K, Morita A, et al. Non-hospital DOT and early diagnosis of tuberculosis reduce costs while achieving treatment success. Int J Tuberc Lung Dis 2012; 16: 828-834. 
8 World Health Organization. The End TB Strategy. Geneva, World Health Organization, 2016. www.who.int/ entity/tb/post2015_TBstrategy.pdf

9 Lönnroth K, Glaziou P, Weil D, et al. Beyond UHC: monitoring health and social protection coverage in the context of tuberculosis care and prevention. PLoS Med 2014; 11: e1001693.

10 Madan J, Lönnroth K, Laokri S, et al. What can dissaving tell us about catastrophic costs? Linear and logistic regression analysis of the relationship between patient costs and financial coping strategies adopted by tuberculosis patients in Bangladesh, Tanzania and Bangalore, India. BMC Health Serv Res 2015; 15: 476.

11 Instituto Nacional Do Seguro Social. Auxílio-doença. Available from: www.inss.gov.br/beneficios/auxilio-doenca/ Date last updated: February 5, 2018. Date last accessed: March 12, 2018.

12 Medeiros M, Britto T, Veras Soares F. Targeted Cash Transfer Programmes in Brazil: BPC and the Bolsa Familia. Brasilia, International Poverty Centre, 2008. www.ipc-undp.org/pub/IPCWorkingPaper46.pdf

13 Gazola Hellmann A. How Does Bolsa Familia Work? Best Practices in the Implementation of Conditional Cash Transfer Programs in Latin America and the Caribbean. Washington, Inter-American Development Bank, 2015. Available from: https://publications.iadb.org/bitstream/handle/11319/7210/How_does_Bolsa_Familia_Work.pdf? sequence $=5$ \&isAllowed $=\mathrm{y}$

14 Ministério da Saúde. Sistema de Informação de Tratamentos Especiais de Tuberculose (SITETB). Available from: http://sitetb.saude.gov.br/sitetb/login.seam;jsessionid=CF67B43BE3A0B2E589E3412DF4953A2E?cid=4790 Date last accessed: January 23, 2018.

15 World Health Organization. Tuberculosis Patient Cost Surveys: A Handbook. Geneva, World Health Organization, 2017. Available from: www.who.int/tb/publications/patient_cost_surveys/en/

16 The World Bank. Official Exchange Rate (LCU per US\$, Period Average). http://data.worldbank.org/indicator/PA. NUS.FCRF?locations=BR\&page $=5$ Date last accessed: December 1, 2017.

17 World Health Organization. WHO Guide to Identifying the Economic Consequences of Disease and Injury. Geneva, World Health Organization, 2009. Available from: www.who.int/iris/handle/10665/137037

18 Ministry of Social Development, World Without Poverty. What is Poverty? https://wwp.org.br/en/what-is-poverty/ Date last accessed: January 10, 2018.

19 Micallef L, Rodgers P. eulerAPE: drawing area-proportional 3-Venn diagrams using ellipses. PLoS One 2014; 9: e101717.

20 International Labour Organization. Transitioning From the Informal to the Formal Economy. Geneva, International Labour Office, 2014. Available from: www.ilo.org/ilc/ILCSessions/103/reports/reports-to-the-conference/WCMS 241897/lang-en/index.htm

21 Wolfe R. Covering the informal sector. Report from a workshop on expanding access to health services and financial protection for people outside the formal employment sector. London, London School of Hygiene and Tropical Medicine, Resilient and Responsive Health Systems (RESYST), 2014. Available from: www.gov.uk/dfidresearch-outputs/covering-the-informal-sector-report-from-a-workshop-on-expanding-access-to-health-services-andfinancial-protection-for-people-outside-the-formal-employment-sector

22 Wagstaff A, Flores G, Hsu J, et al. Progress on catastrophic health spending in 133 countries: a retrospective observational study. Lancet Glob Health 2018; 6: e169-e179.

23 World Bank. The State of Social Safety Nets 2015. Washington, World Bank, 2015. http://documents.worldbank. org/curated/en/415491467994645020/pdf/97882-PUB-REVISED-Box393232B-PUBLIC-DOCDATE-6-29-2015-DOI10-1596978-1-4648-0543-1-EPI-1464805431.pdf

24 Rudgard WE, Evans CA, Sweeney S, et al. Comparison of two cash transfer strategies to prevent catastrophic costs for poor tuberculosis-affected households in low- and middle-income countries: an economic modelling study. PLoS Med 2017; 14: e1002418. 